\title{
Biotechnology and the potential of rhizosphere microorganisms in agricultural practices
}

\author{
Carballo-Sánchez, Marco Polo*; Ferrera-Cerrato, Ronald; Alarcón, Alejandro; \\ Almaraz-Suárez, Juan José
}

Colegio de Postgraduados Campus Montecillo, Carretera México-Texcoco km 36.5, Montecillo, Texcoco, Estado de México, México, C. P. 56230.

* Correspondence: carballo.marco@colpos.mx

Gitation: Carballo-Sánchez, Marco P., Ferrera-Cerrato, R., Alarcón, A., \& Almaraz-Suárez, J. J. (2021). Biotechnology and the potential of rhizosphere microorganisms in agricultural practices. Agro Productividad. https://doi.org/ 10.32854/ agrop.vl4i12.1988

Editor in Ghief: Dr. Jorge Cadena Iñiguez

\section{Received: March 31, 2021.} Accepted: November 21, 2021. Published on-line: December 20, 2021

\section{This work is licensed under a} Creative Commons Attribution-NonCommercial 4.0 International license.

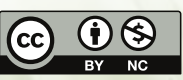

\begin{abstract}
Objective: To perform a brief introspective regarding the biotechnological management of microorganisms in the rhizosphere, its implementation in bioprocesses, and its practical application in field.

Design/methodology/approach: Bibliographic review regarding the beneficial effects of Arbuscular Mycorrhizal Fungi (AMF) and Plant Growth-Promoting Rhizobacteria (PGPR), which can be applied in bioformulations.

Results: There are numerous documented applications of AMF and PGPR — both on laboratory and industrial scale for bioformulation production - aimed to improve crop yield and to provide resistance against abiotic stress and pests. Non-conventional uses are also shown in non-agricultural areas.

Study limitations/implications: AMF and PGPR are widely recognized in agriculture due to their inherent ability to compete in harsh conditions within ecosystems, metabolism versatility, and production of secondary metabolites that enable beneficial interactions with plants and other microorganisms. However, industrial production of AMF presents challenges, as a result of their obligate biotrophs condition and a lack of compatibility with traditional bioprocesses.

Findings/conclusions: The knowledge generated throughout rhizosphere research should be applied in the industry, in order to extend its use in agriculture.
\end{abstract}

Keywords: Biotechnology, Bioprocess, Industrial microbiology, Arbuscular mycorrhiza, Plant growthpromoting rhizobacteria.

\section{INTRODUCTION}

Currently, awareness regarding the risks of agrochemicals has experienced a considerable increase. These materials are regulated and even banned in some countries, because their use has adverse side effects on the environment, the biota, and human health. As a result of the changes that their uncontrolled use has caused to the ecosystems, a search for a method that improves crops conditions, without recurring to chemical products, have been undertaken. From the point of view of the soil ecosystems studies, the knowledge about the

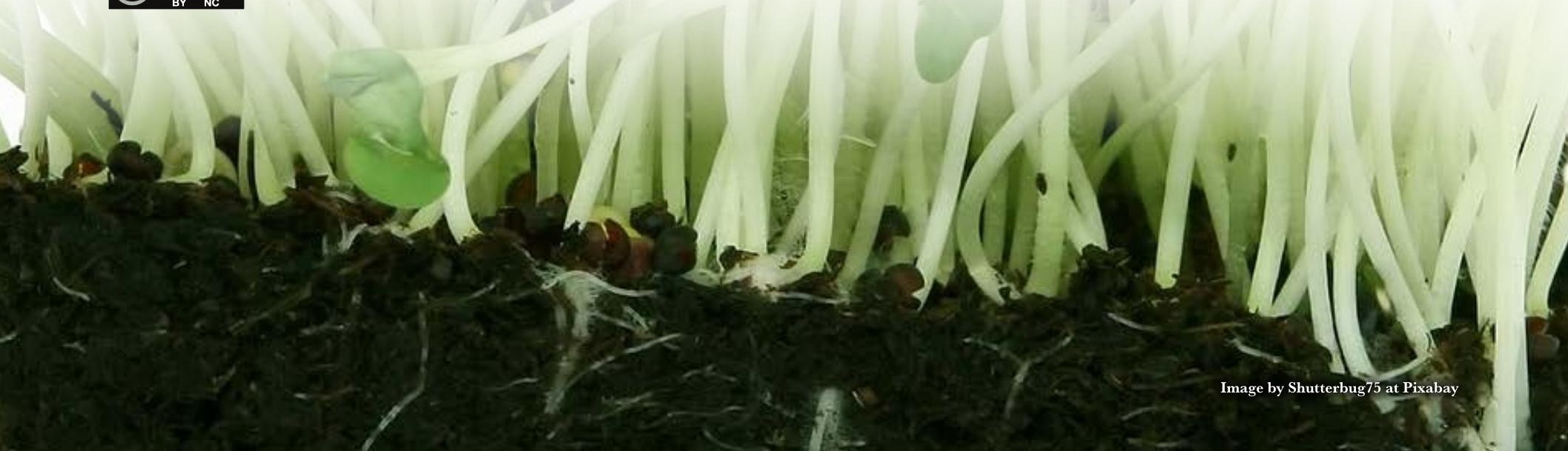


interaction of plants and rhizosphere microorganisms offers a viable alternative to improve agricultural practices, not just increasing fertility, but also providing plants with resistance against pests and abiotic stress.

In the context of agricultural practices, the biotechnical management of rhizosphere microorganisms in the field is compatible with organic agriculture techniques. The market offers bioformulations - which use plant-growth promoting rhizobacteria (PGPR) and arbuscular mycorrhizal fungi (AMF) - to improve crops; therefore, the need to implement more technologies related to favorable biotic interactions is increasing and opens a niche to implement new developments or to improve existing developments.

\section{Biotechnology aimed at the application of microorganisms in agriculture}

Biotechnology is an interdisciplinary approach that uses live organisms to obtain products of overall interest for human activities. This technology uses algae, bacteria, fungi, yeast, plant and higher animal cells, or subsystems of any of them, as well as isolated compounds of live matter (Bhatia and Goli, 2018). This discipline is as old as civilization itself: it allowed the development of plants, the domestication of animals, and the production of food -including cheese, yoghurt, bread, vinegar, beer, and wine (Arfin and Sonawane, 2019). Biotechnology includes several areas that can or cannot involve genetic characterization or manipulation. Although progress in plant and microorganism genetic engineering has benefited agriculture, there are areas that do not involve genetic manipulation — such as classical biotechnology and bioprocesses - and which have great potential, mainly for the improvement of the quality of agricultural products and crop productivity.

Biochemical or bioprocess engineering enables the development of processes and equipment that provide products of interest - mainly on an industrial scale - through fermentation processes that seek to produce greater quantities and achieve a higher quality of a particular product (cells, spores, primary or secondary metabolites) (Doran, 2013). Industrial microbiology is the area of knowledge that studies microorganisms that are handled through bioprocesses. This area deals with large-scale fermentations and compensates the limitations for their application, such as substrata cost and quality, operational costs, purity of the starter culture, nutritional needs of the organisms, product purification, product yield regarding the substrata, and non-optimized metabolic pathways (Behera et al. 2019).

Within the procedures to establish a bioprocess, a strain must be chosen - whether from the environment or a collection-, in order to obtain a highly-concentrated product of interest. Subsequently, the process must be optimized: first in the lab and then at a pilot scale, before escalating it to an industrial level. Optimization means a fair and appropriate use of resources, in order to obtain the maximum potential yield of the desired product. Fermentations are influenced by such variables as: agitation, ventilation, temperature, and $\mathrm{pH}$, as well as more specific elements, depending on the microorganism used for this purpose. All these systems have operational costs - such as power, fuel, water, and maintenance, among other supplies and expenditures - that directly influence the profitability of the process. 
Industrial microbiology has been interested in rhizosphere microorganisms, because their application is relevant to sustainable agriculture (Barea, 2015) and non-agricultural areas. As a result of their favorable interaction with the ecosystem, they promote plant growth and long-term pathogen control, reducing the use of synthetic fertilizers and pestcontrol substances.

Interactions between the plant roots and the rhizosphere microorganisms take place when the plant attracts the symbiotic organism, which interacts with its root. In its turn, the microorganism must distinguish itself as a symbiotic organism, rather than a pathogen; subsequently, it gains a regulated entry into the root. The carbon photosynthetically fixed by the plant (photosynthates) is directly transferred to the below-ground biomass through root exudates, providing nutrients for epiphytic and saprophytic organisms - which accelerate the decomposition of the soil organic matter - or endophytic organisms - which are associated to the plant cells, through $\mathrm{N}$-fixing microorganisms or mycorrhizal symbiosis (Horwath, 2007).

This results in a situation where each organism must take part in a complex and structured communication that enables the successful establishment of the symbiosis. The term "molecular dialogue" refers to chemotaxis and was coined to describe the communication between the plant roots and the microorganisms (Perotto and Baluška, 2012). This process takes places through the production of secondary metabolites, which have different functions, including: signaling molecules, growth regulators, organic acids, enzymes, antibiotics, biopolymers, etc.

\section{Biotechnological management of arbuscular mycorrhizal fungi and significant challenges}

The arbuscular mycorrhiza (AM) is made up of fungi which penetrate the vascular plant roots cortical cells; AM is an advantage for vegetal growth. They promote the absorption of mineral nutrients and water, because their hyphae - which are thinner than the rootscan penetrate small pores that are inaccessible to the roots (Allen, 2011). Not only does AM improve the nutrients that the plants receive, it also enhances their resistance to abiotic stress (salinity, drought, and floods), as well as their resistance to diseases (Berruti et al., 2016). The AM contributes to the degradation of organic matter producing extracellular enzymes and to soil stabilization producing proteins, such as glomalin and hydrophobin (Leinweber et al. 2013). AMFs are considered primary biotic compounds of the soil; therefore, the absence of mycorrhizas is considered abnormal for most vegetable species, resulting in an inefficient functioning of the ecosystem (Jansa and Gryndler, 2010).

$\mathrm{AMF}$ are obligate biotrophs, because they must establish an association inside the plant roots to produce propagules; therefore, the common bioprocesses for the heterotrophic microorganism culture are not favorable for this type of fungi. The AMF production is carried by the plant and its symbiont in different systems: 1. Substrata culture: sand or perlite - in bags, pots, or containers inside a greenhouse-, in non-sterile conditions; it does not require complex techniques and has a low cost, although it is difficult to keep it safe from pollutants and particles (Millner and Kitt, 1992). 2. Substrata free: hydroponic and aeroponic ecosystems, which use nutritive solutions and require precolonized plants. 
These systems allow an improved spore harvest and reduce the risk of contamination; however, they have disadvantages, such as the greater complexity of the infrastructure and the high risk of bacteria and algae contamination of their solutions (Ijdo et al., 2011). 3. In vitro AMF culture in tissue (monoxenic culture): this system may or may not require transformed roots to produce propagules. It prevents contamination throughout the process and enables a more efficient implementation, in a greater scale than the previous two systems (Kokkoris and Hart, 2019). The disadvantages are its high costs and the need for highly-qualified technical staff.

Hard work is being carried out to improve the AMF culture conditions. Currently, no processes that allow the large-scale, low-cost propagule production are available. This is a huge disadvantage for its industrial production and its large-scale application in the field.

Although there are different types of reactors for cultures submerged with mechanical or pneumatic agitation (airlift reactors), they have adverse side effects, such as root asphyxia. This is the result of the low solubility of oxygen in liquid environments $\left(1.22 \times 10^{-3} \mathrm{~mol} \mathrm{dm}{ }^{-3}\right.$ at $25^{\circ} \mathrm{C}$ at 1 atm in pure water) (Xing et al., 2014), which causes root asphyxia and the loss of feasibility. In a liquid culture environment, the lack of oxygen is usually compensated with enough aeration (which also works as an agitation in the airlift reactors) and an increase in the power of the agitation (for reactors with a mechanic agitator). In vegetable tissue cultures, the conditions for the bacteria and filamentous fungi cannot be used, because they produce cell stress and the AMF are not adapted to the said culture conditions. The approach for AMF cultures consists in other techniques which send oxygen to the roots, whether they have been transformed or not, in similar conditions to those of their natural environment, but retaining contact with the culture medium, without producing root asphyxia. Table 1 shows several patents regarding AMF bioformulation production for its application in the field. These bioformulations are made up of spores harvested in in vitro production conditions. Additionally, a proposal to produce AMF propagules in roots - whether they have been transformed or not- using a gas-phase reactor was made. The international WO2019/003240Al patent suggests that, in order to achieve a proper root oxygenation and nutrition, they should be in contact with the disperse culture medium as fog, in a closed system under sterile conditions.

\section{The importance of bioinput for agriculture}

Bioinputs are currently being used as an alternative or complement to conventional agrochemicals. According to their functionality, they are classified as: bioinsecticides, biotech insect repellents, biofungicides, biofertilizers, biostimulants, pest-control substances, and inoculants. This type of preparations may include substances that achieve a desirable nutritional effect or an efficient pest and disease control; they can include plant, mineral, animal, and microbial elements, and even living or latent microorganisms. Inoculants may contain a single or a combination of microorganisms. Their formulas can include other substances. Depending on their effect, they can also be classified as biostimulants, pestcontrol substances, and biofertilizers. 


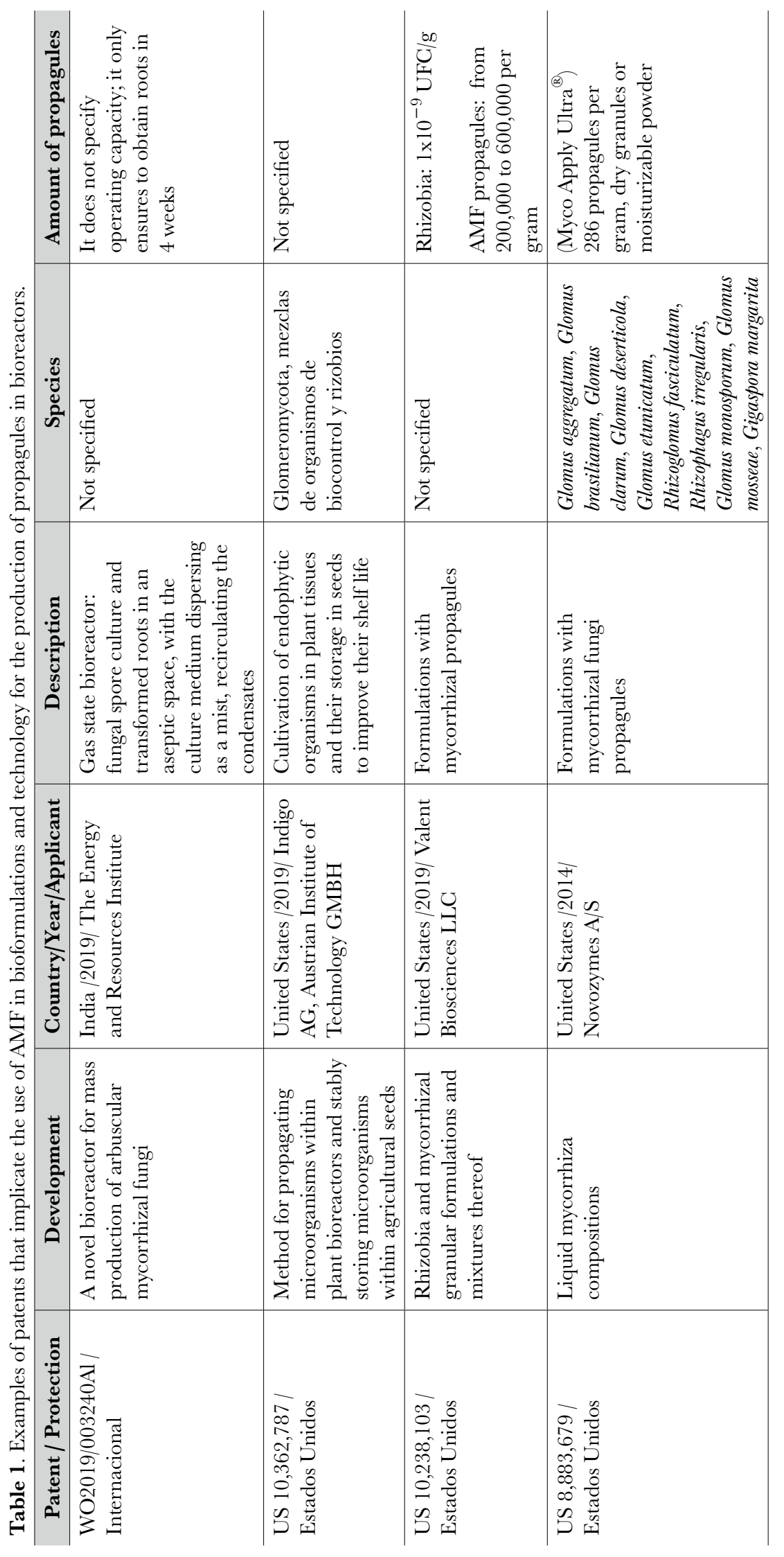


The inoculant production process includes several stages: isolation of the strains with the best characteristics for the objective; efficient lab and field tests; fermentation methods; formulation viability; choosing the appropriate carrier; toxicology; industrial scaling; and quality control (Xavier et al., 2004; O’Callaghan, 2016). Quality control is an aspect that must be particularly emphasized. Several aspects that are included in the regulations of several countries around the world must be taken into account, including: crop effectiveness and persistence; viable microorganism count in the product; survival of the organisms in the carrier; shelf life; carrier sterility; and compatibility with native microbiota. In Mexico, these aspects are governed by the NOM-077-FITO-2000 (https://www.gob.mx/senasica/ documentos/nom-077-fito-2000) standard, which is currently being modified.

\section{Biotechnological management of plant growth-promoting bacteria (PGPB)}

More and more mechanisms through which bacteria favor the promotion of plant growth are discovered every day. They can facilitate the availability of certain nutrients in insoluble forms - for example, in the release of siderophores and organic acids or the fixation of atmospheric nitrogen-, they diminish the competition for the substrate, they produce growth-regulating substances, and they interfere with the signals of antagonistic organisms, etc. (Souza et al., 2015; Ramakrishna et al., 2019). This type of mutualistic interaction allows the plant to improve its conditions, while the microorganisms increase their chances of surviving in a highly competitive environment. PGPB benefit their hosts through various action mechanisms, depending on the species and the colonization and development conditions.

Since survival in the rhizosphere faces highly competitive conditions, bacteria have an extremely high capacity to produce extracellular secondary metabolites (enzymes and other molecules) and to make the most of substrates from several sources and complexities (Sant'Anna et al., 2011; Eida et al., 2020). Table 2 shows various ways in which bacteria groups can be used for agriculture and other non-conventional activities (such as the production of industry-focused metabolites). This versatility is highly appreciated in practical applications, both in agriculture and other areas, including: bioremediation, biorefining, production of food, make-up or medicine additives, production of biopolymers, enzymes, and biosurfactants, etc.

The production of PGPB for their use as inoculants is an alternative to agrochemicals. Additionally, it leads to products with higher quality and greater yield, both individually and mixed with other organisms, such as AMF (Mishra and Arora, 2016).

Gómez-Merino et al. (2014), Ferrera-Cerrato et al. (2016), Mitter et al. (2021), and other researchers have highlighted the importance and need of soil microbiology knowledge to provide greater support for plant nutrition and agricultural production, from a sustainable and innovative point of view.

\section{CONGLUSIONS}

The rhizosphere microorganisms offer promising solutions to achieve a productive, sustainable, and eco-friendly agriculture; they also contribute to the bioremediation of polluted environments and the production of metabolites of interest for non-agricultural 


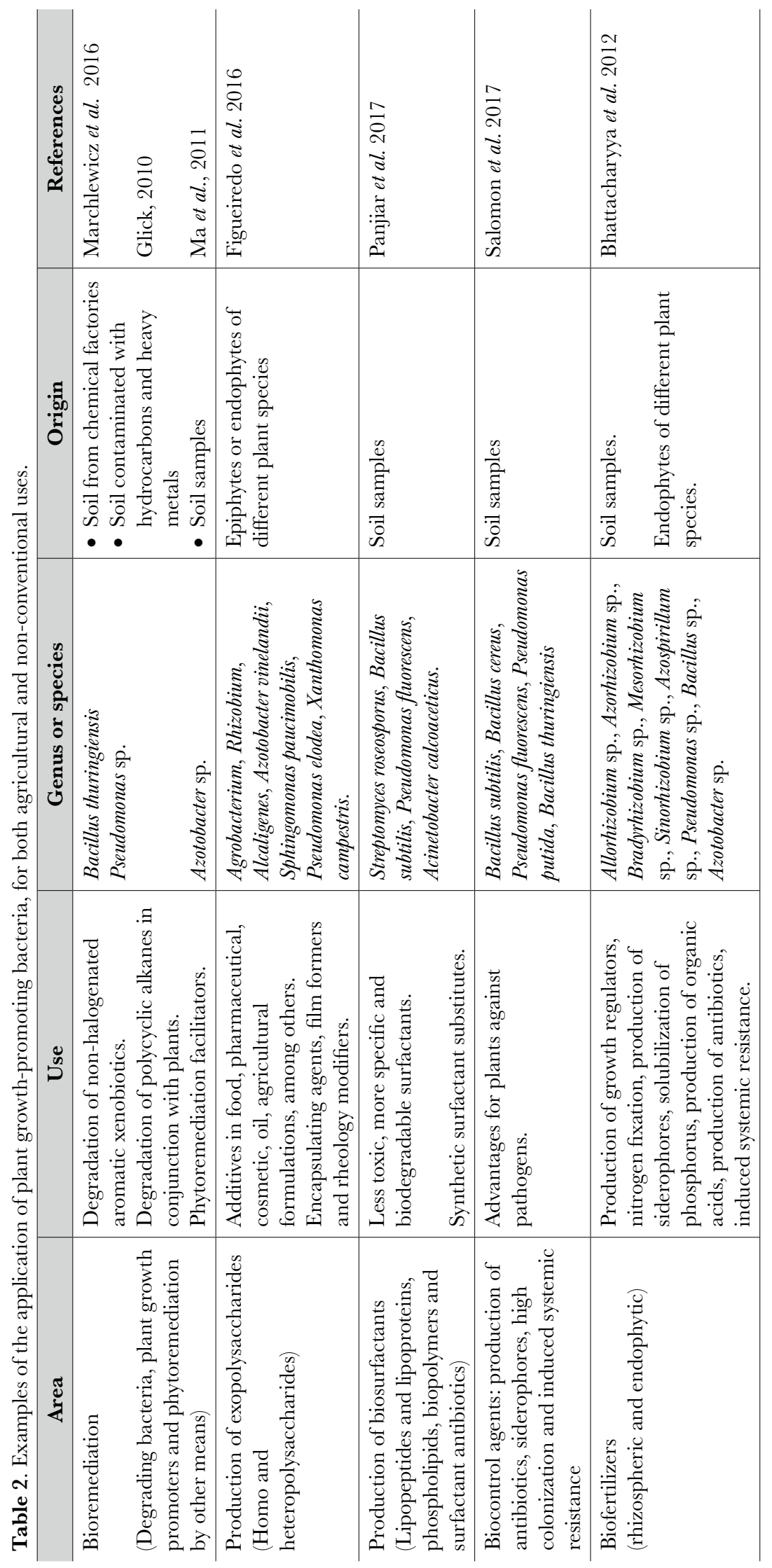


areas. Biotechnology and its various branches provide alternative solutions to problems such as: crop quality, pollution, and the extensive use of agrochemicals. Specifically, they contribute to the establishment of bioprocesses related to the massive production of microorganisms whose effectivity for their extensive use in the field has been proven, depending on the problem that needs to be solved. Therefore, the knowledge about rhizosphere microbiology must establish a close collaboration with agricultural producers and the industries, in order to develop feasible large-scale solutions.

\section{REFERENGES}

Adholeya, A., Mukherjee, G. (2019). Patente internacional N WO 2019/003240 Al. World Intellectual Property Organization. Geneva, Switzerland.

Allen, M.F. (2011). Linking water and nutrients through the vadose zone: a fungal interface between the soil and plant systems. Journal of Arid Land 3(3), 155-163.

Arfin, T., \& Sonawane, K. (2019). Biotechnology: Past to Future. In S. Ul-Islam (Ed.), Integrating Green Chemistry and Sustainable Engineering (pp. 617-645). New Dehli, India: Wiley.

Barea, J.M. (2015). Future challenges and perspectives for applying microbial biotechnology in sustainable agriculture based on a better understanding of plant-microbiome interactions. Journal of Soil Science and Plant Nutrition, 15(2), 261-282. Doi: 10.4067/S0718-95162015005000021

Behera, S.S., Ray, R.C., Das, U., Panda, S.K., Saranraj, P. (2019). Microorganisms in fermentation. In: Essentials in Fermentation Technology (pp. 1-39). Springer, Switzerland.

Berruti, A., Lumini, E., Balestrini, R., Bianciotto, V. (2016). Arbuscular mycorrhizal fungi as natural biofertilizers: let's benefit from past successes. Frontiers in Microbiology, 6, 1559. Doi: 10.3389/fmicb.2015.01559

Bhattacharyya, P.N., Jha, D.K. (2012). Plant growth-promoting rhizobacteria (PGPR): emergence in agriculture. World Journal of Microbiology and Biotechnology, 28(4), 1327-1350. Doi: 10.1007/s11274-011-0979-9

Bhatia, S., Goli, D. (2018). Introduction to Pharmaceutical Biotechnology. Basic techniques and concepts. London, UK: IOP Publishing.

Doran, P. M. (2013). Bioprocess engineering principles. London, UK. Academic Press.

Eida, A. A., Bougouffa, S., L'Haridon, F., Alam, I., Weisskopf, L., Bajic, V. B., Saad, M.M., Hirt, H. (2020). Genome insights of the plant-growth promoting bacterium Cronobacter muytjensii JZ38 with volatile-mediated antagonistic activity against Phytophthora infestans. Frontiers in Microbiology, 11, 369. Doi: 10.3389/fmicb.2020.00369

Ferrera-Cerrato, R., Alarcón, A., Delgadillo-Martínez, J., Almaráz-Suárez, J. J., Pérez-Moreno, J. (2016). Los microorganismos rizosféricos y su impacto en la nutrición vegetal. In: G. Alcántar-González, L.I. TrejoTéllez, F. C. Gómez-Merino, Nutrición de Gultivos. 2da. Ed. (pp. 423-443). Texcoco, México: Colegio de Postgraduados.

Figueiredo M.V.B., Bonifacio A., Rodrigues A.G., de Araujo F.F., Stamford N.P. (2016) Beneficial Microorganisms: Current Challenge to Increase Crop Performance. In: N. Arora, S. Mehnaz, R. Balestrini (Eds.) Bioformulations: for Sustainable Agriculture. New Delhi, India: Springer.

Glick, B.R. (2010). Using soil bacteria to facilitate phytoremediation. Biotechnology advances, 28(3), 367-374. Doi: 10.1016/j.biotechadv.2010.02.001

Gómez-Merino, F.C., Trejo-Téllez, L.I., Alarcón, A. (2015). Plant and microbe genomics and beyond: potential for developing a novel molecular plant nutrition approach. Acta Physiologiae Plantarum 37, 208. Doi: 10.1007/s11738-015-1952-2.

Ijdo, M., Cranenbrouck, S., Declerck, S. (2011). Methods for large-scale production of AM fungi: past, present, and future. Mycorrhiza, 21(1), 1-16.

Horwath, W. (2007). Carbon cycling and formation of soil organic matter. In: Soil microbiology, ecology and biochemistry (pp. 303-339). Academic Press. Doi: 10.1007/s00572-010-0337-z

Jansa J., Gryndler M. (2010). Biotic Environment of the Arbuscular Mycorrhizal Fungi in Soil. In: H. Koltai, Kapulnik, Y. (Eds.), Arbuscular Mycorrhizas: Physiology and Function. (pp. 209-236). Dordrecht, The Netherlands: Springer.

Kokkoris, V., Hart, M.M. (2019). In vitro propagation of arbuscular mycorrhizal fungi may drive fungal evolution. Frontiers in Microbiology, 10, 2420. Doi: 10.3389/fmicb.2019.02420

Leinweber, P., Kruse, J., Baum, C., Arcand, M., Knight, J. D., Farrell, R., Eckhardt, K.-U., Kiersch, K., Jandl, G. (2013). Advances in understanding organic nitrogen chemistry in soils using state-of-the-art analytical techniques. Advances in Agronomy 119, 83-151. Doi: 10.1016/B978-0-12-407247-3.00002-0 
Ma, Y., Prasad, M.N.V., Rajkumar, M., Freitas, H. (2011). Plant growth promoting rhizobacteria and endophytes accelerate phytoremediation of metalliferous soils. Biotechnology advances, 29(2), 248-258. Doi: 10.1016/j.biotechadv.2010.12.001

Marchlewicz, A., Domaradzka, D., Guzik, U., Wojcieszyńska, D. (2016). Bacillus thuringiensis B1 (2015b) is a gram-positive bacteria able to degrade naproxen and ibuprofen. Water, Air, ES Soil Pollution, 227(6), 197. Doi: 10.1007/s1 1270-016-2893-0

Mitter, E.K., Tosi, M., Obregón, D., Dunfield, K.E., Germida, J.J. (2021). Rethinking crop nutrition in times of modern microbiology: innovative biofertilizer technologies. Frontiers in Sustainable Food Systems 5, 606815. Doi: 10.3389/fsufs.2021.606815

Millner, P.D., Kitt, D.G. (1992). The Beltsville method for soilless production of vesicular-arbuscular mycorrhizal fungi. Mycorrhiza 2, 9-15. Doi: 10.1007/BF00206278

Mishra, J., Arora, N.K. (2016). Bioformulations for plant growth promotion and combating phytopathogens: a sustainable approach. In: Bioformulations: For sustainable agriculture (pp. 3-33). New Delhi, India: Springer.

O'Callaghan, M. (2016). Microbial inoculation of seed for improved crop performance: issues and opportunities. Applied Microbiology and Biotechnology, 100(13), 5729-5746. Doi: 10.1007/s00253-016-7590-9

Panjiar, N., Sachan, S.G., Sachan, A. (2017). Biosurfactants: a multifunctional microbial metabolite. In: V. Kalia (Ed.), Microbial Applications (pp. 213-229). Cham, Switzerland: Springer.

Perotto, S., Baluška, F. (2012). Signaling and communication in plant symbiosis. ISBN: 978-3-642-20966-6, Springer, 1-30.

Ramakrishna, W., Yadav, R., Li, K. (2019). Plant growth promoting bacteria in agriculture: Two sides of a coin. Applied Soil Ecology, 138, 10-18. Doi: 10.1016/j.apsoil.2019.02.019

Rillig, M. C. (2004). Arbuscular mycorrhizae, glomalin, and soil aggregation. Canadian Journal of Soil Science, 84(4), 355-363. Doi: 10.4141/S04-003

Salomon, M.V., Pinter, I.F., Piccoli, P., Bottini, R. (2017). Use of plant growth-promoting rhizobacteria as biocontrol agents: induced systemic resistance against biotic stress in plants. In: Microbial Applications (Vol. 2, pp.133-152) ISBN: 978-3-319-52669-0, Springer.

Sant'Anna, F.H., Almeida, L.G., Cecagno, R., Reolon, L.A., Siqueira, F.M., Machado, M. R., Vasconcelos, A.T., Schrank, I.S. (2011). Genomic insights into the versatility of the plant growth-promoting bacterium Azospirillum amazonense. BMC Genomics, 12(1), 409. Doi: 10.1186/1471-2164-12-409

Souza, R. D., Ambrosini, A., Passaglia, L. M. (2015). Plant growth-promoting bacteria as inoculants in agricultural soils. Genetics and molecular biology, 38(4), 401-419. Doi: 10.1590/S1415-475738420150053.

Verma, A.S., Agrahari, S., Rastogi, S., Singh, A. (2011). Biotechnology in the realm of history. Journal of Pharmacy and Bioallied Sciences, 3(3), 321-323. Doi: 10.4103/0975-7406.84430

Xavier, I. J., Holloway, G., Leggett, M. (2004). Development of rhizobial inoculant formulations. Crop Management, 3(1), 1-6. Doi: 10.1094/CM-2004-0301-06-RV

Xing, W., Yin, M., Lv, Q., Hu, Y., Liu, G., Zhang, J. (2014). Oxygen solubility, diffusion coefficient, and solution viscosity. In: W. Hing, G. Yin, J. Zhang (Eds.), Rotating electrode methods and oxygen reduction electrocatalysts (pp. 1-31). Amsterdam, The Netherlands: Elsevier. 